\title{
Study on micro hydro-mechanical deep drawing using finite element method
}

\author{
Xiaoguang $\mathrm{Ma}^{1}$, Jingwei Zhao ${ }^{1}$, Wei $\mathrm{Du}^{2}$, Xin Zhang ${ }^{2}$, Laizhu Jiang ${ }^{2}$ and Zhengyi Jiang ${ }^{1, a}$ \\ ${ }^{1}$ School of Mechanical Materials and Mechatronic Engineering, University of Wollonggong, NSW 2522, Australia \\ ${ }^{2}$ Stainles Steel Technical Centre, Baosteel Research Institude (R\&D Centre), Baoshan Iron \& Co., Ltd, Shanghai 200431, China
}

\begin{abstract}
A numerical model was established to investigate the micro hydro-mechanical deep drawing process of austenitic stainless steel 304 foil ( $0.05 \mathrm{~mm}$ thickness). Due to the miniaturisation of the specimen size, the effect of grain size, gap distance and radial pressure during drawing process could be prominent. The results indicate that the appropriate radial pressure and gap distance could improve the limit drawing ratio (LDR) of manufactured cylindrical cups by reducing the friction resistance. The maximum LDR obtained in the present work reaches 3.2, which is much higher than that obtained by conventional deep drawing process.
\end{abstract}

\section{Introduction}

In recent decade, micro forming has been an attractive research topic due to its wide applications in fabricating micro parts for micro electro mechanical system, microelectronic technology and precision machinery [1] With high productivity, high utilisation of raw material and good mechanical properties, micro forming process is considered to be significant for development of manufacturing engineering. Micro deep drawing, which is a key branch of micro forming process, is widespread used in a variety of fields including automobile body parts, painless needles and micro electronic component. Thus, the significance of micro deep drawing investigation should not be ignored.

Furushima et al. [2] studied the effects of oxidation and surface roughening on limiting drawing ratio (LDR) in dieless drawing process of austenitic stainless steel 304. It was found that the LDR in dieless drawing strongly depends on heating temperature. The effect of die/blank holder and punch radius on LDR in angular deep drawing dies was studied by Ozek et al. [3]. It was concluded that both the LDR and punch force increased with increasing the die/blank holder and punch radius. The microdeep drawability of very thin sheet steels was studied by Saotome et al. [4] to clarify drawing characteristics. For sheet steels of below $0.2 \mathrm{~mm}$ thickness, the LDR was found to decrease with the increase of relative punch diameter $\left(D_{p} / \mathrm{t}\right)$ from 10 to 100 . It is worth mentioned that for cases with $D_{p} / \mathrm{t}=10$, the bending effect is dominant since blank holder pressure has little effect on drawability. A new deep drawing method using incremental electromagnetic assisted stamping with radial magnetic pressure was proposed by Cui et al. [5]. Compared to conventional deep drawing, the new method could significantly increase the value of material flow, decrease the tensile stress and thickness reduction at flange area, thereby improving LDR. Irthiea et al. [6] proposed a technique through adopting an initial gap between the adjustment ring and blank holder using flexible tools in which the blank holder was moveable and supported by a particular spring that provided the required holding force Both numerical and experimental results showed that relatively bigger initial gaps and smaller friction coefficient increased the formability whereas the friction coefficient between the blank and flexible die did not make a big difference.

Significant work has been done by researchers on deep drawing process to obtain high LDR, which is defined to be the ratio of the maximum blank diameter that can be safely drawn into a cup without flange to the punch diameter. Sato et al. [7] designed and manufactured new apparatus for micro-complex-shape components. It was found that an appropriate counter pressure during hydroforming process could eliminate the generation of wrinkles and reduces friction force, thereby improving drawing performance. The cylindrical cups with LDR of 2.1 have been successfully produced using designed tools. The diamond like carbon film coated blank holders and dies were designed by Gong et al. [8] to reduce the friction effect. The average friction coefficient of 0.169 was reached during micro deep drawing process and the cups were well formed with LDR of 2.1. Abdelmaguid et al. [9] proposed a dynamic programming method to reduce the number of drawing stages through heat treatment. The shell diameters at different stages could be optimised with a novel combination of dynamic programming, thereby improving LDR. Mostafapur et al. [10] investigated the pulsating blank holder effect on drawing to improve the

\footnotetext{
a Corresponding author: jiang@uow.edu.au
} 
formability of aluminum 1050 alloy by means of numerical and experimental methods, and found that the pulsating blank holder increased the depth of cylindrical parts without partial thinning and tearing compared with the static blank holder. The key parameters influencing deep drawing performance were investigated and optimised by Zein et al. [11] using finite element modelling. The recommended value of die shoulder radius, punch nose radius, fluid friction coefficient and radial clearance were given to increase LDR. Besides, too much blank holding force was found to induce significant thinning phenomenon. Vollertsen and $\mathrm{Hu}$ [15] studied the effect of punch velocity on friction coefficient and they also investigated the LDR with different friction conditions. Gau et al. [14] designed singles dies for a whole manufacture process in order to obtain products with high LDR with one stage drawing and two stages ironing at high temperatures. The influence of die/blank holder and punch radius on LDR was studied by Ozek and Bal [16], and it was found that the LDR could be effectively improved by increasing the die/blank holder angle.

Based on existing publications, even though a relative high LDR could be obtained, it is still no more than 2.1 for conventional one stage drawing.

In this study, austenitic stainless steel 304 blank was drawn through micro deep drawing with radial pressure by using FEM. The purpose of this work is to obtain high LDR relative to previous work through optimisation of key processing parameters. The effects of the average grain size, radial pressure and gap distance were discussed to indicate the role of key parameters in the micro deep drawing process.

\section{FE modelling}

\subsection{Solution method}

Given that significant deformation could be observed during micro deep drawing process, the whole forming process was considered to be nonlinear to describe the elastic-plastic behaviour of austenitic stainless steel 304 . The Newton-Raphson iterations were subsequently performed within an increment step to acquire the equilibrium condition between the externally applied load and the internal structural resistance [21]. The scheme is given by

$$
x_{n+1}=x_{n}-\frac{f\left(x_{n}\right)}{\frac{d f\left(x_{n}\right)}{d x}}
$$

The iterative procedure would be terminated when following condition applies.

$$
\left|x_{r+1}-x_{r}\right|<\varepsilon
$$

where $\varepsilon$ is a value that depends on the accuracy set in advance and on machine precision.

\subsection{Flow rule}

In metal plasticity, it is typically assumed that the plastic strain increment and the normal to the pressure-dependent yield surface have the same direction. Therefore, when the material begins its plastic deformation, the plastic strain increment could be defined as:

$$
d \varepsilon_{p}=d \lambda \frac{\partial f}{\partial \sigma}
$$

where $d \lambda>0$ is a hardening parameter, the function $f$ is the plastic potential function that describes the relationship between the stress and plastic strain.

\subsection{Damage model}

The ductile damage evolution was also defined for investigation. Besides, Holloman hardening law was considered to describe the work hardening effect of material. The Hollomon equation is given below

$$
\overline{\sigma_{\gamma}}=K\left(\varepsilon_{0}+\bar{\varepsilon}\right)^{n}
$$

where $\overline{\sigma_{Y}}$ is the effective stress, $K$ is the strength constant, $\varepsilon_{0}$ and $\bar{\varepsilon}$ are the pre-strain and effective strain respectively, and $n$ is the strain hardening exponent. The damage would be generated when strain rate reaches 0.8 .

\subsection{Material model}

The material used in this research is an austenitic stainless steel (304) ultrathin foil with thickness of 0.05 $\mathrm{mm}$. To eliminate the effect of divergent grain properties on deformation mode, Voronoi diagram is utilised in numerical model.

The Voronoi diagram is the tuple of cells $\left(R_{k}\right)$, which is the set of all points in whose distance to site $P_{k}$ is not greater than their distance to the other sites $P_{j}(j \neq k)$. The equation could be written as:

$$
R_{k}=\left\{x \in X \mid d\left(x, P_{k}\right) \leq d\left(x, P_{j}\right)\right\}(j \neq k)
$$

Generally, there are two ways to generate Voronoi tessellation in commercial software ABAQUS /CAE. One way is to directly run the program in MATLAB and write PY files, then import file into ABAQUS and mesh the model. This method is convenient and fast, however, a great number of elements would be generated with this method, leading to great time consumption in further investigation. Moreover, the quality of elements is quite poor, making it hard to ensure the high accuracy of final result. Another common method is to mesh the model in ABAQUS first, then run the program in MATLAB. Based on the obtained results, the INP file could be reedited and imported to ABAQUS program. With this way, the amount of elements could be determined by users and a relatively high accuracy could be achieved despite much more time would be spent in pre-processing. In this study, the latter method was chosen to set up the numerical 
model of blank. To investigate the effect of grain size on micro deep drawing process, three average grain sizes were applied in this study. Figure 1 shows the Voronoi diagram of workpiece utilised in this study.

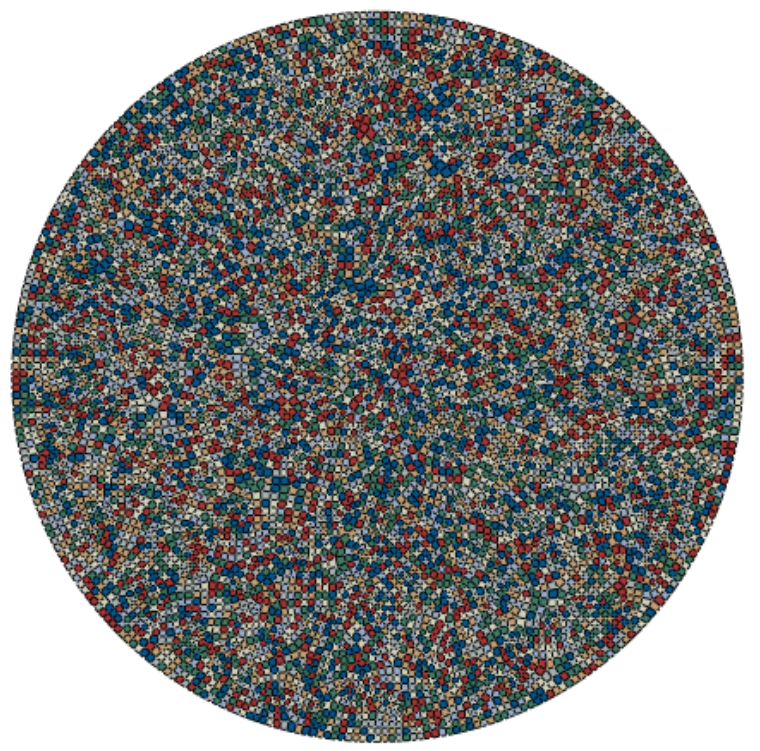

Figure 1. Voronoi diagram of blank with 49555 grains

Since the geometry feature of grains was obtained in Voronoi diagram, all grains should be assigned with certain elastic-plastic properties to show the deformability of individual grains. Hardness describes the resistance to plastic deformation, therefore, the hardness of grains from micro hardness test was considered to be effective to evaluate the grain heterogeneity. From Figure 2 , it can be observed that 7 groups of Vickers hardness values are obtained to represent 7 grain properties in austenitic stainless steel 304, the inhomogeneity coefficient $\xi$ represents the ratio of the hardness at each category divided to the average hardness. Based on results acquired from micro hardness tests, all grains are considered to be described with bilinear isotropic hardness model, with the same Young's modulus and dissimilar tangent modulus. As shown in Figure 3, seven classes of heterogeneity coefficients are utilised to describe the plastic performance of material with Young's modulus of $192 \mathrm{GPa}$, and initial yield stress $\sigma_{s}$ of $205 \mathrm{MPa}$.

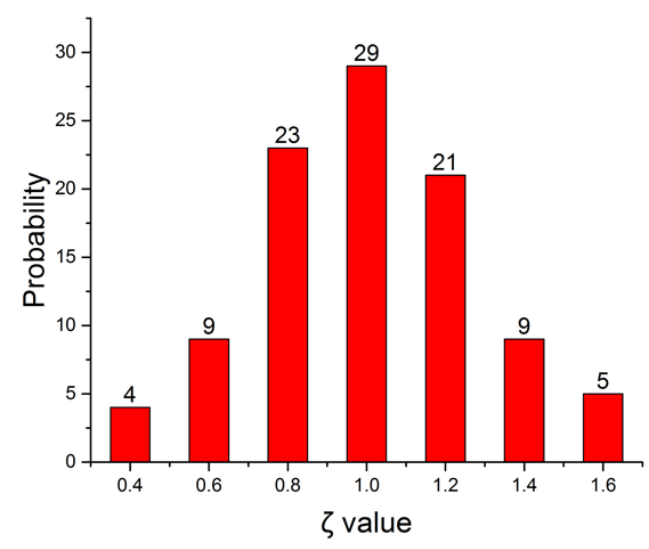

Figure 2. Proportion of grains with inhomogeneity coefficients

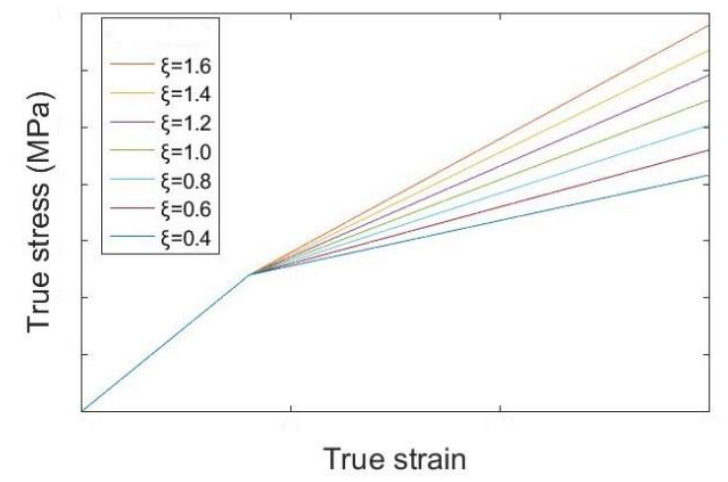

Figure 3. The flow stress curves with different inhomogeneity coefficients

Other parameters used in this study are shown in Table 1. Density, Young's modulus and Possion's ratio are obtained from tensile tests while the $\mathrm{F}$ and $\mathrm{n}$ values followed Saotome [19].

Table 1. Material properties used in simulation

\begin{tabular}{lllll}
\hline $\begin{array}{l}\text { Density } \\
\left(\mathrm{g} \cdot \mu \mathrm{m}^{-1}\right)\end{array}$ & $\begin{array}{l}\text { Young's modulus } \\
(\mathrm{GPa})\end{array}$ & $\begin{array}{l}\text { Possion's } \\
\text { ratio }\end{array}$ & $\begin{array}{l}\text { F-value } \\
(\mathrm{GPa})\end{array}$ & $n$-value \\
\hline $7.93 e^{-12}$ & 192 & 0.25 & 1.55 & 0.44 \\
\hline
\end{tabular}

\subsection{Simulation condition}

The austenitic stainless steel foil and tools were meshed with 8-node linear brick, reduced integration, hourglass control elements (C3D8R). The properties of tools are shown in Table 2 and the dimension of microtools used for micro deep drawing is listed in Table 3. The dimension of tools was optimised with numerical simulation and these parameters were found to be beneficial for drawability of workpiece in this study. Besides, full constrains were assigned to both two parts and a velocity of $0.4 \mathrm{~mm} / \mathrm{s}$ is defined for punch during drawing process. The whole drawing process is carried out at room temperature. Given that the drawing process is completed in several seconds, the variance of temperature during forming process is negligible in this study.

Table 2. Properties of tools

\begin{tabular}{ll}
\hline Density $\left(\mathrm{kg} / \mathrm{m}^{3}\right)$ & Young's modulus $(\mathrm{GPa})$ \\
\hline 8000 & 177
\end{tabular}

Table 3. Dimension of experimental tools

\begin{tabular}{lllll}
\hline $\begin{array}{l}\text { Blank } \\
\text { diameter } \\
(\mathrm{mm})\end{array}$ & $\begin{array}{l}\text { Punch } \\
\text { diameter } \\
(\mathrm{mm})\end{array}$ & $\begin{array}{l}\text { Punch } \\
\text { corner } \\
\text { radius } \\
(\mathrm{mm})\end{array}$ & $\begin{array}{l}\text { Die } \\
\text { diameter } \\
(\mathrm{mm})\end{array}$ & $\begin{array}{l}\text { Die } \\
\text { corner } \\
\text { radius } \\
(\mathrm{mm})\end{array}$ \\
\hline 2.64 & 0.8 & 0.1 & 0.9 & 0.3 \\
\hline
\end{tabular}

The FE model of micro deep drawing process is illustrated in Figure 4. 

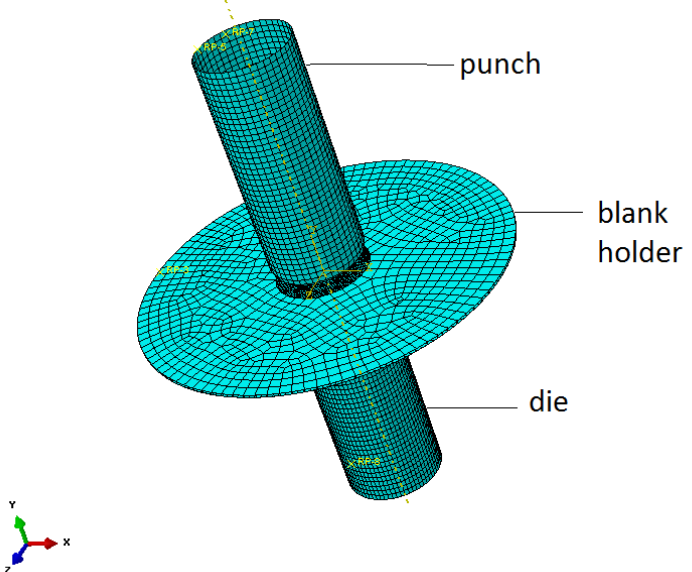

Figure 4. The FE of micro deep drawing process

\section{Results and discussion}

\subsection{Effect of average grain size}

For micro forming process, the effect of average grain size is quite significant due to size effect. When the average grain size increases, the number of grains at thickness direction would be reduced, causing that the deformation of individual grain become dominant during forming process. Instead, with smaller average grain size and more grains at thickness direction, the increasing grain boundaries would weaken the influence of dislocation and slip systems, thereby reducing the effect of crystal plasticity.

Figure 5 presents the equivalent plastic strain distribution of micro deep drawing process with different grain sizes. The forming limit is found to increase with grain size ranging from 0.015 to $0.025 \mathrm{~mm}$. However, when the average grain size below $0.015 \mathrm{~mm}$, that is, there are only one or two grains at thickness direction, and the LDR would be much worse due to the different behaviours of individual grains and different performance of crystal plasticity. This finding is also supported by experiments conducted by $\mathrm{Xu}$ et al. [23].

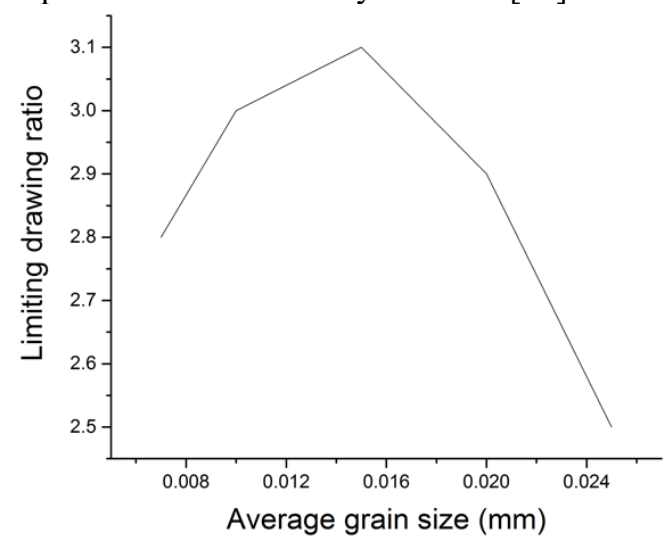

Figure 5. The equivalent plastic strain distribution of micro deep drawing process with different grain sizes

\subsection{Effect of hydro-pressure}

In micro deep drawing process, one of the key reasons leading to failure is the friction between die and blank at flange area, to reduce the effect of friction, radial pressure is applied in this study to improve the formability of workpiece. It is concluded by Wang et al. [24] that a radial pressure could reduce the drawing force and increase LDR. However, it should be noted that too much radial pressure would also give a rise to the occurrence of wrinkles. Moreover, Cui et al. [25] advocated that radial pressure could significantly decrease the tensile stress and thickness reduction at flange area, thereby improving the formability of material.

Figure 6 shows the dependence of LDR on radial pressure. The maximum LDR obtained is 3.2, which is much higher than that of conventional deep drawing (2.1). It can also be observed that with the radial pressure increases from 0 to $240 \mathrm{MPa}$, the LDR rises from 1.8 to 3.2. The enhancement of LDR with increasing the radial pressure is mainly due to the fact that the radial pressure is effective to reduce the stress at flange area and punch force. By applying appropriate radial pressure, the friction effect could be minimised, reducing the cracks at flange area. However, with the range from 240 to 400 $\mathrm{MPa}$, the LDR decreases with increasing radial pressure due to cracks and wrinkles generated from excess radial pressure. Therefore, it can be concluded that an optimal value of radial pressure could promote the LDR, which matches the conclusions from Wang et al. [24] and Cui et al[25].

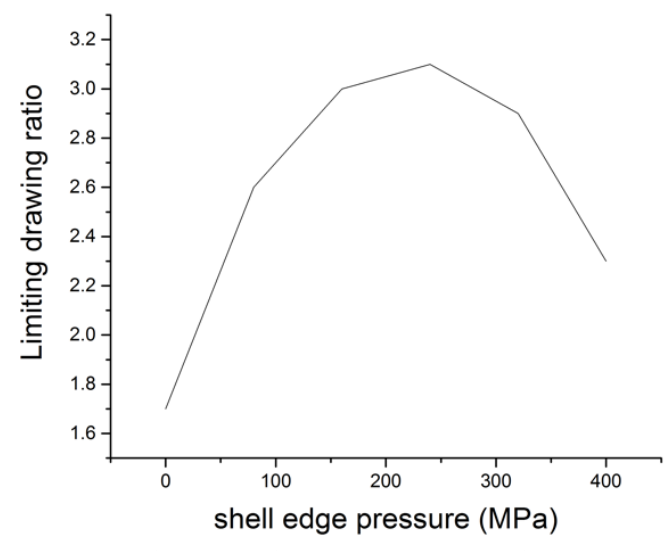

Figure 6. The dependence of LDR on radial pressure

\subsection{Effect of gap distance}

In micro deep drawing process, the gap distance between blank holder and blank is one of most crucial parameters in formability of materials. Irthieea et al. [26] concluded that the reduction of initial gaps increased the thickness reduction especially at the side wall of formed product. Besides, it was further announced that a higher initial gaps could improve the LDR of obtained cups. However, too much gap would also increase the occurrence of wrinkles. Therefore, a balance is required to select an optimal gap distance, which critically affects the formability of cylindrical cups. This point is supported by Gavas and Izciler [27] who declared that excess blank 
holder gap would cause excessive wrinkling and buckling.

Figure 7 shows the dependence of LDR on initial gap. The LDR is observed to increase from 2.8 to 3.2 with the increase of initial gap from 0 to $0.005 \mathrm{~mm}$, which indicates that a larger gap distance would promote the formability of foil, however, when gap distance increases from 0.005 to $0.01 \mathrm{~mm}$, the occurrence of wrinkles would prevent drawing process and reduce the LDR. Thus, it is recommended to use a higher initial gap below limitation in the case of generation of wrinkles.

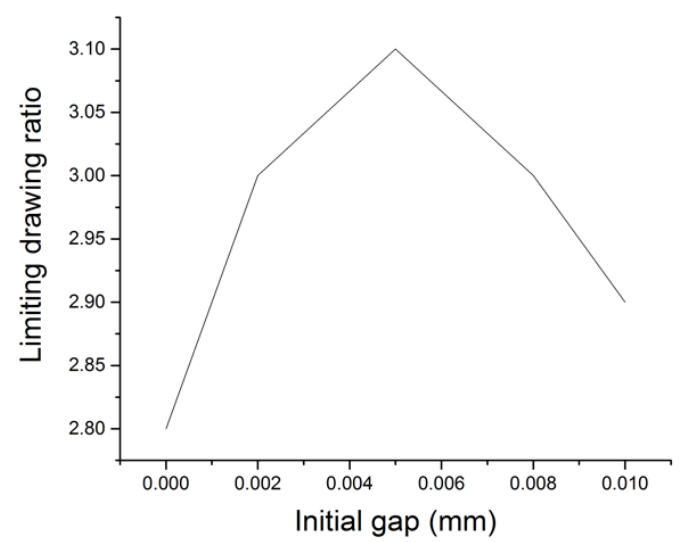

Figure 7. The dependence of LDR on initial gap

\section{Conclusions}

In this paper, a numerical model was established to investigate the formability of austenitic stainless steel 304 cups with consideration of the effects of radial pressure, grain size and initial gap distance. Based on numerical results, several conclusions are drawn as follows:

(1) The LDR for austenitic stainless steel foil (0.05 thick) with suitable radial pressure attains 3.2 , which is 1.6 times of the conventional deep drawing.

(2) Suitable relative punch diameter in micro deep drawing should be applied to minimise the bending resistance and to avoid fractures generated during forming process.

(3) The increase of initial gaps gives a rise to LDR. Use of a higher initial gap is recommended to increase formability. However, the gap distance should not exceed the limitation beyond which wrinkles will be caused.

\section{Acknowledgements}

The first author would like to thank the financial support by IPTA scholarship from University of Wollongong for his PhD study. The study is also supported by Baosteel Australia Joint Centre (BAJC).

\section{References}

1. F. Gong, Z. Yang, Q. Chen, Z. Xie, J. Yang, Precision Eng. 42, 224 (2015)

2. T. Furushima, Y. Imagawa, K. Manabe, T. Sakai, J. Mater. Process. Technol. 223, 186 (2015)
3. C. Ozek, M. Bal, Int. J. Adv. Manuf. Technol. 40, 1077 (2009)

4. Y. Saotome, K. Yasuda, H. Kaga, Japan J. Mater. Process. Technol. 113, 641 (2001)

5. X.H. Cui, J.H. Mo, J.J. Li, Procedia Eng. 81, 813 (2014)

6. I. Irthiea, G. Green, S. Hashim, A. Kriama, J. Mach. Tools Manuf. 76, 21 (2014)

7. H. Sato, K. Manabe, K. Ito, D. Wei, Z. Jiang, J. Mater. Process. Technol. 224, 233 (2015)

8. F. Gong, B. Guo, C. Wang, D. Shan, Diamond Relat. Mater. 20, 196 (2011)

9. D. Min, B. Jeon, H.Kim, N. Kim, J. Mater. Process. Technol. 54, 230 (1995)

10. A. Molotnikov, R. Lapovok, C.F. Gu, C.H.J. Davies, Y. Estrin, Mater. Sci. Eng. A 550, 312 (2012)

11. Z.T. Xu, L.F. Peng, X.M. Lai, M. W. Fu, Mater. Sci. Eng. A 611, 345 (2014)

12. A. Mostafapur, S. Ahangar, R. Dadkhah, Int. J. Adv. Manuf. Technol. 69, 1113 (2013)

13. H. Zein, M. EI-Sherbiny, M. Abd-Rabou, M. EI Shazly, American J. Mech. Eng. 1, 20 (2013)

14. JT. Gau, S. Teegala, KM. Huang, TJ. Hsiao, BT. Lin, J. Manuf. Process. 15, 298 (2013)

15. F. Vollertsen, Z.Y. Hu, Prod. Eng. Res. Dev. 4,553 (2010)

16. C. Özek, M. Bal, Int. J. Adv. Manuf. Technol. 40,1077 (2009)

17. L. Peng, F. Liu, J. Ni, X. Lai, Mater. Des. 28,1731 (2007)

18. C.H. Chen, H.T. Gau, R.S. Lee, Mater. Manuf. Process. 24,1256 (2009)

19. Y. Saotome, K. Yasuda, H. Kaga, J. Mater. Process. Technol. 641 (2001)

20. G. Faraji, M.M. Mashhadi, R Hashemi, J. Manuf. Sci. Technol. 3,262 (2010)

21. F. Qu, Z. Jiang, H. Lu, Int. J. Mech. Sci. 105, 182 (2016)

22. Z. Jiang, H. Lu, D. Wei, K.Z. Linghu, X. Zhao, X. Zhang, D. Wu, Procedia Eng. 81, 2463 (2014)

23. Z.T. Xu, L.F. Peng, X.M. Lai, M.W. Fu, Mater. Sci. Eng. A 611, 345 (2014)

24. H. Wang, L. Gao, M. Chen, J. Mech. Sci. 53,793 (2011)

25. X. Cui, J. Mo., J. Fang, J. Li, J. Procedia Eng. 81, 813 (2014)

26. I. Irthiea, G. Green, S. Hashim, A. Kriama. Int. J. Mach. Tools Manuf. 76, 21 (2014)

27. M. Gavas, M. Izciler, J. Mater. Des. 28, 1641 (2007) 